\title{
Healthcare workers' attitudes to and compliance with infection control guidelines in the operating department at the University Hospital of the West Indies, Jamaica
}

\author{
C. David McGaw ${ }^{1}$, Ingrid Tennant ${ }^{1}$, Hyacinth E Harding ${ }^{1}$, Shamir O Cawich ${ }^{1}$, Ivor W Crandon ${ }^{1}$, CA Walters ${ }^{2}$ \\ ${ }^{1}$ Department of Surgery, Radiology, Anaesthesia and Intensive Care, University of the West Indies, Jamaica \\ ${ }^{2}$ Health Research Resource Unit, Dean's Office, Faculty of Medical Sciences, \\ University of the West Indies, Jamaica
}

doi: 10.3396/ijic.v8i3.023.12

\begin{abstract}
Surgical operations provide opportunities for the transmission of infection between patients and healthcare workers (HCWs) and between patients. This risk may increase in under-developed and developing countries by low compliance with infection control (IC) policies and precautions. This study investigated HCWs attitude and compliance with infection control practices in the operating department (OD) of a Jamaican teaching hospital, with the objective of obtaining data to design evidence-based interventions. A single-centre, cross-sectional, descriptive study, using a self-administered questionnaire, was conducted between March and May 2009. Ninety doctors and forty-two nurses, representing $73 \%$ and $75 \%$ respectively of their total OD population, participated in the study. Reported compliance was low: only $17 \%$ of all participants were compliant with all of the seven infection control policies inquired into. The results also showed that HCWs were selective in what practices they adhered to: reported rates of compliance were high for hand-washing $(100 \%)$, use of gloves $(98 \%)$, use of gowns $(83 \%)$ and facemasks $(87 \%)$; but low for use of eye protection mask $(56 \%)$, not re-sheathing needles (46\%) and changing clothes when exiting and re-entering the OD (55\%). Discrepancies were observed between attitude and compliance rates in such cases as 'use of facemasks'- low favourableattitude (68\%) but high compliance; 'use of eye protection masks'- high favourable-attitude (100\%) but low
\end{abstract}

\author{
Corresponding Author \\ Dr. C.D. McGaw \\ The Department of Surgery, Radiology, Anaesthesia and Intensive Care \\ The University of the West Indies, Kingston 7, Jamaica, West Indies \\ Email: cdmcgaw@cwjamaica.com
}


compliance; and 'not re-sheathing needles'- high favourable attitude (86\%) but low compliance. Overall, nurses had higher favourable attitude $(p<0.001)$ and compliance rates $(p=0.008)$ than physicians. To improve HCWs adherence to guidelines, interventions must take account of those factors which determine human behaviour.

\section{Key words}

Disease transmission, infectious; Infection control, standards; attitude of health personnel; operating rooms, microbiology

\section{Introduction}

Healthcare associated infections place a significant economic burden on the healthcare system. ${ }^{1,2}$ Infection control (IC) practices are paramount to minimizing healthcare associated infections. However, low compliance with Universal Precautions (UP) and Standard Precautions (SP) has been reported in a number of studies. Not many of these studies are from low and middle income countries, which may have cultural, managerial, financial and environmental factors that could influence compliance differently from developed countries. Even fewer of these studies specifically investigate the practices of healthcare workers $(\mathrm{HCWs})$ in the operating department (OD). This study sought to determine baseline attitude towards and compliance with infection control guidelines among HCWs in the OD of a Jamaican teaching hospital.

Health care-associated infections, particularly those that are surgery-related, are important causes of perioperative morbidity and mortality, prolonged hospital stay and increased costs. ${ }^{1,2} \mathrm{HCW}$ s may be responsible for patient-to-patient transmission of infection. In addition, there is the risk of patient-to-practitioner transfer that may result in life- or career-threatening consequences. Infection control interventions, such as hand hygiene, safe disposal of needles, use of gloves, gowns and facemasks where appropriate, are vital for prevention and limitation of nosocomial infections and form an important part of modern OD policies., ${ }^{3,4}$ However, these policies are only effective if consistently practiced by HCWs and compliance has been shown to be suboptimal in numerous international studies. ${ }^{5-7}$ Compliance rates from as low as $30 \%$ for facemask use and $38 \%$ for use of eye protection have been reported. ${ }^{8}$ Hand washing, the most basic of infection control measures, has been reported to be adhered to only approximately $40 \%$ of the time. ${ }^{6}$
The risk of suboptimal compliance may be increased in developing countries like Jamaica due to such factors as inadequate funding for infection control educational programs, high patient load per HCW, crowded operating rooms, and inadequate resources (e.g., personal protective equipment (PPE), sharps containers, operating theatre scrubs and hand wash detergent dispensers). The authors' personal observation and complaints from infection control personnel suggested that non-compliance was a significant problem in our hospital. This study aims to establish baseline attitude towards and compliance with specific OD guidelines resulting in data from which appropriate interventions may be constructed.

\section{Methods}

The University Hospital of the West Indies (UHWI) is a university-affiliated teaching institution located in Kingston, Jamaica and is a tertiary care referral centre for the entire island. There are seven multi-purpose operating rooms in the OD that are managed by the Department of Surgery. An infection control policy manual was drafted by the Department of Surgery to detail the existing protocols aimed at achieving infection control in the OD. Although infection control protocols were enforced by OD staff, there were no structured infection control education programs at the time of the study.

Approval was obtained from the local ethics committee at the UHWI to interview HCWs for this study. We created a database of all HCWs performing duties at the OD between March 1 and May 30, 2009. We excluded those who were: responsible for drafting infection control policies, unwilling to participate in the study; and non-clinical OD personnel, e.g. porters. Permission to participate in this study was sought from any HCW who met the inclusion criteria. 
A standardized self-administered questionnaire was used as the instrument to collect information from the participants. Data were collected on demographic variables and participants' awareness of the existence of their own OD infection control manual. Participants' attitude and compliance regarding specific infection control policies were examined and recommendations for improving compliance were solicited. For hand washing and use of gloves, participants were asked about their practice with regards to exposure to body fluids. For use of gowns and eye protection, participants were asked about their practice with regards to procedures or patient care activities that were likely to generate splashes or sprays of body fluids. For the use of facemasks, participants were asked about their attitudes and practices in relation to non-scrubbed personnel only. Attitudes were assessed using a 5 point Likert-type scale (strongly agree, agree, don't know, disagree, strongly disagree), and practice with a 4 point scale (always, usually, occasionally, never). Regarding attitude, 'strongly agree' and 'agree' responses were considered 'favourable' whilst 'disagree' and 'strongly disagree' responses were considered 'unfavourable'. Regarding compliance, 'always' and 'usually' were considered 'compliance' whilst 'occasionally' and 'never' were considered 'noncompliance', except in the case of recapping of needle, where the reverse would apply.

The Statistical Package for Social Sciences (SPSS) version 12.0 and STATA version 10 were used for storage and analysis of the data. Descriptive statistics were generated as appropriate. Chi-squared and Fisher's exact tests were used to assess associations as well as t-tests used to compare means between variables of interest.

\section{Results}

\section{Demographics}

The questionnaire was completed by $132 \mathrm{HCWs}$, 90 doctors $(68 \%)$, and 42 nurses $(32 \%)$. This sample represented $74 \%$ of the total population of HCWs working full-time in the OD during the study period (73\% of doctors and $75 \%$ of nurses). There were 56 males $(42 \%)$, most of whom were physicians $(n=54)$. Almost $70 \%$ of respondents were between the ages of 21 and 39 years. The majority of respondents were within 10 years of graduating from their respective programs
(60\% among physicians and $74 \%$ among nurses). Anaesthetists (35\%), obstetrician/gynaecologists $(18 \%)$, and general surgeons $(18 \%)$ were the largest groups of HCWs among the physicians.

\section{Acquaintance with the Infection Control OD Manual} Sixty-eight participants (52\%) knew of the existence of an infection control manual for the OD, however, only $23(18 \%)$ had actually read it. Nineteen percent (19\%) stated that they had never been taught any infection control policies for the OD. Most HCWs obtained their knowledge of the recommended practices through oral communication with colleague nurses in $86(65 \%)$ cases and doctors in $59(45 \%)$ cases. Yet others gained information from their own research in $67(51 \%)$, signs in the OD in $41(31 \%)$ and formal presentation/ training courses in $37(28 \%)$ cases.

\section{Attitude and Compliance with Specific Guidelines Handwashing}

Ninety-six percent (96\%) of respondents strongly agreed that hand-washing is the most effective method of preventing the spread of infection (Table I). In practice, $87 \%$ claimed that they always and $13 \%$ usually wash their hands after touching body fluids. However, $27 \%$ of respondents (31\% physicians and $15 \%$ nurses) admitted that they could get frustrated into not washing their hands when antiseptic soap is not readily accessible (Table II).

\section{Use and Disposal of Sharps}

The vast majority of respondents, $86 \%$, agreed with the UP guideline that needles should never be recapped (Table III). However, in actual practice, only $16,12 \%$, of respondents stick rigidly to the guideline (i.e., never recap) while $42 \%$ occasionally recap. On the other hand, 39\% usually and 7\% always recap their used needles.

\section{Facemasks}

Despite the fact that only $68 \%$ of respondents agreed with the policy that 'facemasks should always be worn by non-scrubbed staff', the declared rate of compliance with the policy was high (86\%).

\section{Changing Clothes When Leaving Theatre}

Although $70 \%$ of all respondents agreed with changing clothes on exit and re-entry into the OD, only 55\% 


\section{Table I. Distribution of Attitude Rates by Occupation}

\begin{tabular}{|c|c|c|c|c|c|}
\hline & $\begin{array}{r}\text { Strongly } \\
\text { Agree }\end{array}$ & Agree & $\begin{array}{l}\text { Don't } \\
\text { know }\end{array}$ & Disagree & $\begin{array}{c}\text { Strongly } \\
\text { Disagree }\end{array}$ \\
\hline \multicolumn{6}{|l|}{ Physicians } \\
\hline Hand washing* & $50(56 \%)$ & $35(39 \%)$ & --- & $5(5 \%)$ & --- \\
\hline Gloves* & $83(92 \%)$ & $7(8 \%)$ & --- & --- & --- \\
\hline Facemask ${ }^{\S}$ & $25(28 \%)$ & $25(28 \%)$ & $10(11 \%)$ & $30(33 \%)$ & --- \\
\hline Eye protection* & 83 (93\%) & $6(7 \%)$ & --- & --- & --- \\
\hline Gowns* & $73(85 \%)$ & $13(15 \%)$ & --- & --- & --- \\
\hline $\begin{array}{l}\text { Changing clothes on exit } \\
\text { and re-entry to the OD }\end{array}$ & $26(29 \%)$ & $30(34 \%)$ & $3(3 \%)$ & $24(27 \%)$ & $6(7 \%)$ \\
\hline \multicolumn{6}{|l|}{ Nurses } \\
\hline Hand washing* & $31(74 \%)$ & $11(26 \%)$ & --- & --- & --- \\
\hline Gloves* & $39(93 \%)$ & $3(7 \%)$ & --- & --- & --- \\
\hline Facemask ${ }^{\S}$ & $27(66 \%)$ & $12(30 \%)$ & $1(2 \%)$ & $1(2 \%)$ & --- \\
\hline Eye protection* & $42(100 \%)$ & --- & --- & --- & --- \\
\hline Gowns* & $38(95 \%)$ & $2(5 \%)$ & --- & --- & --- \\
\hline $\begin{array}{l}\text { Changing clothes on exit } \\
\text { and re-entry to the OD }\end{array}$ & $30(74 \%)$ & $5(12 \%)$ & $1(2 \%)$ & $4(10 \%)$ & $1(2 \%)$ \\
\hline
\end{tabular}

*Use on exposure to body fluids

$\S$ Use by non-scrubbed personnel

were compliant with this guideline. There was marked disparity between responses from physicians and nurses. Nurses had a greater favourable- attitude rate (85\%) than physicians (63\%) and were more likely to be compliant ( $68 \%$ vs. $49 \%$ ). Among the physicians, the anaesthetists had the lowest favourable-attitude (32\%) and compliance rates (7\%) with this policy.

\section{Personal Protective Equipment (PPE) -} Eye Protection, Gloves and Gowns

PPE refers to a variety of barriers and masks used to protect mucous membranes, airways, skin, and clothing from contact with infectious agents (gloves, gowns, eye shields). All respondents agreed that the use of eye protection, gloves and gowns was necessary when attending to patients where splashes of body fluids were likely. However, only 56\% declared compliance with use of eye protection, $52 \%$ amongst physicians and $65 \%$ amongst nurses. Ninety-eight percent (98\%) of physicians and nurses stated that they wore gloves and $83 \%$ that they wore gowns, when touching nonintact skin.

Overall, nurses had both a significantly higher rate of favourable-attitude towards the guidelines than physicians $(p<0.001)$ and a greater tendency to be compliant with them $(p=0.008)$. Only $17 \%$ of all participants were compliant with all seven infection control policies: physicians $13 \%$ and nurses $26 \%$. 


\section{Table II. Distribution of Compliance Rates by Occupation}

\begin{tabular}{|c|c|c|c|c|}
\hline & Always & Usually & Occasionally & Never \\
\hline \multicolumn{5}{|l|}{ Physicians } \\
\hline Handwashing* & $78(87 \%)$ & $12(13 \%)$ & --- & --- \\
\hline $\begin{array}{l}\text { Frustated into not } \\
\text { washing hands }\end{array}$ & $3(3 \%)$ & $8(9 \%)$ & $16(18 \%)$ & $61(70 \%)$ \\
\hline Gloves* & $45(50 \%)$ & $43(48 \%)$ & $2(2 \%)$ & --- \\
\hline Facemasks ${ }^{\S}$ & $41(46 \%)$ & $35(39 \%)$ & $13(15 \%)$ & --- \\
\hline Eyeprotection* & $24(27 \%)$ & $22(25 \%)$ & $22(25 \%)$ & $21(23 \%)$ \\
\hline Gowns* & $27(31 \%)$ & $43(49 \%)$ & $18(20 \%)$ & --- \\
\hline Recapping Needles & $7(8 \%)$ & $45(51 \%)$ & $33(37 \%)$ & $4(4 \%)$ \\
\hline $\begin{array}{l}\text { Changing clothes on on exit and } \\
\text { re-entry to the OD }\end{array}$ & $18(20 \%)$ & $26(29 \%)$ & $24(27 \%)$ & $21(24 \%)$ \\
\hline \multicolumn{5}{|l|}{ Nurses } \\
\hline Handwashing* & $37(88 \%)$ & $5(12 \%)$ & --- & --- \\
\hline $\begin{array}{l}\text { Frustated into not } \\
\text { washing hands }\end{array}$ & $3(7 \%)$ & $1(3 \%)$ & $2(5 \%)$ & $34(85 \%)$ \\
\hline Gloves* & $36(86 \%)$ & $5(12 \%)$ & $1(2 \%)$ & -- \\
\hline Facemasks ${ }^{\S}$ & $27(64 \%)$ & $10(24 \%)$ & $4(10 \%)$ & $1(2 \%)$ \\
\hline Eyeprotection* & $13(32 \%)$ & $13(32 \%)$ & $13(32 \%)$ & $1(3 \%)$ \\
\hline Gowns* & $26(62 \%)$ & $12(29 \%)$ & $4(9 \%)$ & --- \\
\hline Recapping needles & $2(5 \%)$ & $7(17 \%)$ & $21(50 \%)$ & $12(28 \%)$ \\
\hline $\begin{array}{l}\text { Changing clothes on on exit and } \\
\text { re-entry to OD }\end{array}$ & $19(51 \%)$ & $6(16 \%)$ & $12(33 \%)$ & --- \\
\hline
\end{tabular}

* Use on exposure to body fluids

$\S$ Use by non-scrubbed personnel

\section{Recommendations for improving HCWs knowledge} and compliance with infection control policies

Respondents were requested to select one or more of the listed recommendations as well as include any other(s) they wished. To improve HCW's knowledge of matters related to OD infection control policies, $79 \%$ recommended formal training sessions, $70 \%$ recommended providing reading materials, and $23 \%$ suggested requiring certification of competence. To improve HCWs compliance with the policies, $72 \%$ recommended providing evidence-based proof of the policies, 37\% recommended appealing to HCWs selfdiscipline, and $37 \%$ recommended the implementation of sanctions. 


\section{Table III. Classification of respondents' attitude and practice with common IC guidelines}

\begin{tabular}{lrrrr} 
& \multicolumn{2}{c}{ Attitude } & Practice \\
\cline { 2 - 5 } & Favourable & Unfavourable & Compliant & Non-compliant \\
\hline Handwashing & $127(96 \%)$ & $5(4 \%)$ & $127(100 \%)$ & 0 \\
Use of gloves & $132(100 \%)$ & 0 & $129(98 \%)$ & $3(2 \%)$ \\
Use of gowns & $130(100 \%)$ & 0 & $108(83 \%)$ & $22(7 \%)$ \\
Eye protection & $131(100 \%)$ & 0 & $72(56 \%)$ & $57(44 \%)$ \\
Use of facemasks by & $89(68 \%)$ & $31(24 \%)$ & $113(86 \%)$ & $18(14 \%)$ \\
non-scrubbed personnel & & & & \\
Changing clothes on exit & $91(70 \%)$ & $35(27 \%)$ & $69(55 \%)$ & $57(45 \%)$ \\
and re-entry to OD & $113(86 \%)$ & $18(14 \%)$ & $70(53 \%)$ & $61(47 \%)$ \\
Not re-sheathing needles & & & &
\end{tabular}

\section{Discussion}

Our study confirmed that HCWs in the OD at the UHWI had suboptimal levels of compliance with standard infection control guidelines: only $17 \%$ of all participants were compliant with all seven infection control policies. This is in keeping with the findings of general studies on HCW compliance with infection control policies conducted in developed nations..$^{7-10}$

The study also supported previous reports that HCWs are selective in their adherence to individual guidelines. Wide variations in compliance with individual infection control guidelines have been reported in many studies. For hand-washing, compliance rates range from $27-86 \%$, with a mean of $52 \% .{ }^{10}$ Regarding PPE, Gammon et al. reported that glove, gown and eye protection compliance rates were, on average, $62 \%$ (range $11-98 \%$ ), 57\% (range $8-93 \%$ ), and 38\% (range $0-92 \%$ ), respectively. ${ }^{10}$ Gammon also found the mean compliance rate for facemask use to be $30 \%$ (range $4-55 \%)$.

These various studies, done over large regions and over a long span of time, reflect the ubiquitous and intractable nature of the problem of non-compliance with infection control guidelines. As humans are at the centre of the problem, theories of human behaviour applied to the data obtained in these studies may provide insight into the underpinnings of noncompliance and assist with the design and formulation of interventions. These acts of non-compliance are referred to as 'violations.'11 Violations are defined as deliberate actions that are not intended to cause harm but that do deviate from established protocols or practice. Beatty and Beatty classify these violations into one of three areas: routine violations (tolerated by the organizational culture of the workplace and are not intended to cause harm), exceptional violations (atypical actions of individuals that are not tolerated by the organizational culture, and are not intended to do harm), and malevolent acts (intended to do harm and are usually criminal; these are rare). ${ }^{12}$ The origin of these violations is in attitudes and motivation. ${ }^{13} \mathrm{An}$ approach that has been used to examine violations is referred to as the theory of planned behaviour (TPB). ${ }^{14,15}$ The TPB states that a person's intention to engage in a given behaviour can be predicted by three factors: attitude to behaviour, which reflects the person's beliefs about the possible consequences of the behaviour, subjective norm, which reflects the perceived level of social approval for the behaviour; and perceived behavioural control, which reflects the person's beliefs about the level of control he or she has over the behaviour. The TPB, and its three predictors of behaviour, appears applicable to the data obtained from this study. 


\section{Attitude to behaviour}

For a number of the policies inquired into, favourable attitude correlated with compliance and unfavourable attitude with non-compliance. Examples of the former include hand-washing (favourable attitude - 96\%, compliance - $87 \%$ always and $13 \%$ usually), and use of personal protective equipment, (gloves: favourable attitude - 100\%, compliance - 98\%; and gowns: favourable attitude - 100\%, compliance - 83\%). An example of the latter is 'changing clothing on exit and re-entry to the OD'; overall, only $70 \%$ of respondents agreed with this requirement and only 55\% reported always/usually complying with it. This correlation was even more striking for one subcategory of respondents, namely anaesthetists: only $32 \%$ of anaesthetists agreed with it and only $7 \%$ declared compliance with it. A possible reason for this is that anaesthetists, particularly those on emergency duty, often have concurrent responsibilities which extend beyond the confines of the OD; they may find the frequent changing of clothing inconvenient and, in emergency situations, potentially dangerous, due to the inevitable time delay. Opposition to this policy may be strengthened by the perception that this policy is not based on credible scientific evidence. ${ }^{16,17}$

\section{Subjective norm}

Subjective norm appears to be an influential factor in determining respondents' compliance with the policy requiring non-scrubbed staff to routinely wear facemasks. This is thought to be so because, despite a low percentage of respondents $(68 \%)$ agreeing with the policy, $86 \%$ of them reported that they routinely wore a facemask. The low agreement with the policy may be due to general scepticism of the scientific evidence-base for this practice. ${ }^{18-20}$ However, at the UHWI, senior nursing and medical colleagues generally request strict adherence to this policy and this expectation may underpin the high level of compliance amongst the respondents.

\section{Perceived behavioural control}

An example of perceived behavioural control is thought to be provided by the results obtained in regard to the wearing of eye protection. Although all respondents agreed with the policy, only $56 \%$ always or usually comply with it. This may be attributed to the frequent unavailability of these specialized masks, most likely a result of financial constraints, a factor which, outside of the lobbying by staff, is generally beyond their control.

Of particular interest, and requiring greater analysis, is the discrepancy between the attitude and behaviour of respondents regarding the re-sheathing of needles. This is especially important because of the high risk of transmission of blood-borne infections associated with needle-stick injuries. Globally, needle stick injuries (NSIs) are the most common source of occupational exposures to blood and the primary cause of bloodborne infections of HCWs. ${ }^{21,22}$ The two most common causes of NSIs are two-handed recapping (resulting in $10-25 \%$ of injuries) and the unsafe collection and disposal of sharps waste. ${ }^{23,24}$ The results showed that despite the fact that $86 \%$ of respondents agreed with the UP/SP guideline that needles should never be re-sheathed after use, as many as $46 \%$ admitted to regularly re-sheathing their needles. Two reasons which may account for this are: 'convenience' they may want to re-use the syringe/needle unit (e.g., anaesthetists caring for a surgical patient often administer drugs in incremental or repeat doses rather than by a single bolus), in which case they would not wish to leave it uncapped for fear of accidental NSI, and 'perceived low safety risk' - respondents may feel that they can safely re-sheath their needles without sticking themselves. Also, regarding this guideline, the HCW acts as an independent practitioner and assumes greater latitude to not comply with the guideline as the risk of NSI during re-capping is to oneself only and not to a colleague or patient. Both 'attitude to behaviour' and 'perceived behavioural control' appear to be underlying factors influencing this behaviour.

Why nurses had significantly greater favourableattitude $(p<0.001)$ and compliance rates $(p=0.008)$ than their physician counterparts is unclear. It may be that physicians assume greater latitude to question the basis and importance of specific guidelines, especially those they consider to be based more on tradition than on their efficacy in reducing the transmission of infection. Staff and trainee nurses, on the other hand, have a greater tendency to stick more rigidly to the dictates of the OD nurse manager and established practices. 
Education-related recommendations were the ones most frequently proposed by respondents to improve $\mathrm{HCWs}^{\prime}$ knowledge of the OD infection control policies. Others included certification of competence in infection control prior to OD assignments and the provision of a clear and accessible OD infection control manual. The fact that only $18 \%$ of respondents had ever read the OD infection control manual supports the need for the latter recommendation. It must be noted, however, that the guidelines inquired into in this study were well-known UP/SP and other standard practices which are readily evident once one is assigned to the OD. While education and knowledge are obviously important, studies have shown that education and knowledge improvement, by themselves, does not always translate to improved compliance. ${ }^{8}$ Rather, the chances of successful intervention may be improved by incorporating the behaviour theories in planning an intervention program. Compliance can also be improved by highlighting consequences and using senior personnel as mentors, to promote social approval of these behaviours. Other interventions which can be used to supplement education programs include providing data on hospital acquired infections, reinforcing protocols vigorously and regularly monitoring infection control practices.

\section{Limitations}

The major limitation of this study was that the assessment of compliance with infection control guidelines was based on the respondents own determination and admission rather than independent observation of their actual practice. It could be expected that HCWs would over-report their level of compliance with infection control policies in an effort to please their supervisors. The study is also limited by the fact that it is a single-centre survey.

\section{Conclusions}

In conclusion, this study demonstrates that HCWs in the OD at the UHWI have reported sub-optimal levels of compliance with selective infection control practices. This is in keeping with results from international studies. The study further demonstrated that discrepancies exist between, on the one hand, HCWs' attitude towards a guideline, and, on the other hand, their actual practice. This suggests that multiple and, at times, complex factors may be at play in determining a HCW's behaviour, which, in turn, might explain why compliance to infection control precautions is internationally suboptimal, and the problem so intractable to various forms of interventions. While educating $\mathrm{HCW}$ on matters relating to infection control is an important intervention, an awareness of the factors which determine human behaviour and application of these theories to individual guidelines may be necessary for there to be significant improvements in compliance. Further studies will then be necessary to evaluate the efficacy of any intervention administered.

\section{References}

1. Plowman R, Graves N, Griffin MAS, et al. The rate and cost of hospital-acquired infections occurring in patients admitted to selected specialties of a district general hospital in England and the national burden imposed. / Hosp Infect 2001; 47: 198-209. http://dx.doi.org/10.1053/jhin.2000.0881

2. Fry DE. The economic costs of surgical site infection. Surg Infect (Larchmt) 2002; 3(Suppl 1): S37-43. http://dx.doi. org/10.1089/sur.2002.3.s1-37

3. Bolyard EA, Talban OC, Williams WW, Pearson ML, Shapiro NC, Deitchman SD. Guideline for infection control in healthcare personnel. Am J Infect Control 1998; 26: 289-354. http://dx.doi.org/10.1016/S0196-6553(98)80015-1

4. Garner J. Hospital Infection Control Practices Advisory Committee: guideline for isolation precautions in hospitals. Am J Infect Control 1996; 24: 25-52.

5. Osborne S. Influences on compliance with standard precautions among operating room nurses. Am J Infect Control 2003; 31: 415-423. http://dx.doi.org/10.1067/mic.2003.68

6. Boyce JM, Pittet D. Guideline for hand hygiene in health-care settings: recommendations of the Healthcare infection Control practices Advisory Committee and the HICPAC/SHEA/APIC/ IDSA Hand Hygiene Task Force. Infect Control Hosp Epidemiol 2002; 23(12 suppl): S3-40. http://dx.doi.org/10.1086/503164

7. Stein AD, Makarawo TP, Ahmad MFR. A survey of doctors' and nurses' knowledge, attitudes and compliance with infection control guidelines in Birmingham teaching hospitals. J Hosp Infect 2003; 54: 68-73. http://dx.doi.org/10.1016/S01956701(03)00074-4

8. Gammon J, Morgan-Samuel H, Gould D. A review of the evidence for suboptimal compliance of healthcare practitioners to standard/universal control precautions. I of Clinical Nursing 2008; 17: 157-167.

9. Gershon RRM, Vlahov D, Felknor S, et al. Compliance with universal precautions among workers at three regional hospitals. American Journal of Infection Control 1995; 23: 225-236. http://dx.doi.org/10.1016/0196-6553(95)90067-5

10. Pittet D, Mourouga P, Perneger TV, and the Members of the Infection Control Program. Compliance with handwashing in a teaching hospital. Ann Intern Med 1999; 130: 126-130.

11. Reason J, Parker D, Lawton R. Organizational controls and safety: the varieties of rule-related behavior. I Occup Org Psychol 1998; 71: 289-304. http://dx.doi. org/10.1111/j.2044-8325.1998.tb00678.x

12. Beatty PCW, Beatty SF. Anaesthetists' intentions to violate safety guidelines. Anaesthesia 2004; 59: 528-540. http:// dx.doi.org/10.1111/j.1365-2044.2004.03741.x 
13. Reason J. Human Error. Cambridge: Cambridge University Press, 1990. http://dx.doi.org/10.1017/CBO9781139062367

14 Ajzen I. The theory of planned behavior. Organizational Behavior and Human Decision Processes 1991; 50: 179-211. http://dx.doi.org/10.1016/0749-5978(91)90020-T

15. Ajzen I. From intentions to actions: a theory of planned behavior. In: Beckman J. ed. Action control: from Cognitions to Behaviors. New York: Springer, 1985; 11-39.

16. Roxburgh M, Gall P, Lee K. A cover up? Potential risks of wearing theatre clothing outside theatre. The Journal of Perioperative Practice 2006; 16: 30-33.

17. Woodheady K, Taylorz EW, Bannisterx G, Chesworth T, Hoffman P, Humphreys $\mathrm{H}$. Behaviours and rituals in the operating theatre. A report from the Hospital Infection Society Working Party on Infection Control in Operating Theatres. Journal of Hospital Infection 2002; 51: 241-255.

18. Mitchell NJ, Hunt S. Surgical facemasks in modern operating rooms - a costly and unnecessary ritual? Journal of Hospital Infection 1991; 18: 239-242. http://dx.doi.org/10.1016/01956701(91)90148-2

19. Beck WC. The surgical mask: another sacred cow? AORN J 1992; 55: 955-957. http://dx.doi.org/10.1016/S00012092(07)70339-3
20. Orr NW. Is a mask necessary in the operating theatre? Ann $R$ Coll Surg Eng 1981; 63: 390-392.

21. Updated U.S. Public Health Service Guidelines for the Management of Occupational Exposure to HBV, HCV and HIV and Recommendations for Post Exposure Prophylaxis. MMWR 2001; 50(RR11): 1-42.

22. Health Protection Agency. Eye of the needle: United Kingdom Surveillance of Significant Occupational Exposure to Bloodborne Viruses in Healthcare Workers. Centre for Infections; London: Health Protection Agency; November 2006.

23. Centers for Disease Control. Update: Universal precautions for prevention of transmission of human immunodeficiency virus, hepatitis B virus and other bloodborne pathogens in healthcare settings. Morbidity and Mortality Weekly report 1988; 37: 377-382.

24. Occupational safety and Health Administration. Enforcement procedures for the occupational exposure to bloodborne pathogens. Directive number CPL2-2.44D; 1999 and epic2, $\# 18$. 